\title{
Biologia reprodutiva da reófita Dyckia brevifolia Baker (Bromeliaceae), no Rio Itajaí-Açu, Santa Catarina, Brasil ${ }^{1}$
}

\author{
JULIANA MARCIA ROGALSKI²,5, ADEMIR REIS ${ }^{3}$, MAURÍCIO SEDREZ DOS REIS ${ }^{4}$ e \\ KARINA VANESSA HMELJEVSKI ${ }^{3}$
}

(recebido: 7 de agosto de 2007; aceito: 18 de agosto de 2009)

\begin{abstract}
Reproductive biology of the rheophyte Dyckia brevifolia Baker (Bromeliaceae), on the Itajaí-Açu River, Santa Catarina, Brazil). The species Dyckia brevifolia Baker presents disjunctive populations and restricted distribution. Dyckia brevifolia is a policarpic species with clonal propagation. The reproductive biology of this species was studied on the banks of the Itajaí-Açu River, Santa Catarina, Brazil. The floral characteristics, the nectar production and the behavior of floral visitors were studied. To characterize the reproductive system, five treatments were conducted: agamospermy, spontaneous pollination, self-pollination, cross-pollination and control. Each inflorescence presented $60.4 \pm 14.5$ flowers and $58.3 \pm 13.3$ fruits and the fruit/flower ratio was 0.97. The average number of seeds per fruit was $129.6 \pm 24.3$. The flowers opened from the base to the apex of the inflorescence and the number of opened flowers per inflorescence and day was $6.8 \pm 1.2$. Flower anthesis occurs along the day and the flower lasts a day and half. The average volume and concentration of nectar was $30.5 \mu \mathrm{L}$ and $25.7 \%$, respectively. The main floral visitors were bees, hummingbirds and butterflies, being the hummingbird Amazilia versicolor Vieillot the main pollinator. This species also was pollinated by bees of the genera Xylocopa and Bombus. Regarding the reproductive system, the results indicate that $D$. brevifolia is self-compatible and that agamospermy can occur. The self-compatibility presented for this species, as well as the floral visitors' behavior indicate that the main pollination forms are self-pollination and geitonogamy.
\end{abstract}

Key words - agamospermy, Bromeliaceae, Dyckia brevifolia, pollination, self-compatibility

RESUMO - (Biologia reprodutiva da reófita Dyckia brevifolia Baker (Bromeliaceae), no Rio Itajaí-Açu, Santa Catarina, Brasil). A espécie Dyckia brevifolia Baker apresenta populações disjuntas e distribuição restrita. Dyckia brevifolia é uma espécie policárpica com propagação clonal. A biologia reprodutiva desta espécie foi estudada nas margens do Rio Itajaí-Açu, Santa Catarina, Brasil. As características florais, a produção de néctar e os visitantes florais foram estudados. Para caracterizar o sistema reprodutivo foram conduzidos cinco tratamentos: agamospermia, autopolinização espontânea, autopolinização manual, polinização cruzada e controle. Cada inflorescência apresentou 60,4 \pm 14,5 flores e 58,3 \pm 13,3 frutos e a razão fruto/flor foi de 0,97 . O número médio de sementes por fruto foi de 129,6 $\pm 24,3$. As flores abrem da base para o ápice da inflorescência e o número de flores abertas por dia por inflorescência foi em média de 6,8 $\pm 1,2$. A antese floral ocorre ao longo do dia e a flor tem duração de um dia e meio. O volume e a concentração médios do néctar foram de 30,5 $\mu \mathrm{L}$ e 25,7\%, respectivamente. Os principais visitantes florais foram abelhas, beija-flores e borboletas, sendo o beija-flor Amazilia versicolor Vieillot o principal polinizador. Esta espécie também foi polinizada por abelhas dos gêneros Xylocopa e Bombus. Com relação ao sistema reprodutivo, os resultados indicam que $D$. brevifolia é autocompatível e que a agamospermia pode ocorrer. A autocompatibilidade apresentada pela espécie, bem como o comportamento dos visitantes florais indicam que as principais formas de polinização promovidas são a autopolinização e a geitonogamia.

Palavras-chave - agamospermia, autocompatibilidade, Bromeliaceae, Dyckia brevifolia, polinização

1. Parte da tese de doutorado da primeira autora, Programa de PósGraduação em Recursos Genéticos Vegetais, Universidade Federal de Santa Catarina, Centro de Ciências Agrárias, Departamento de Fitotecnia.

2. Instituto Federal do Rio Grande do Sul, Rodovia RS 135, km 25, Distrito Engenheiro Luiz Englert, Caixa Postal 21, 99170-000 Sertão, RS, Brasil.

3. Universidade Federal de Santa Catarina, Centro de Ciências Biológicas, Departamento de Botânica, Laboratório de Ecologia Florestal, Trindade, Caixa Postal 476, 88040-900 Florianópolis, SC, Brasil.

4. Universidade Federal de Santa Catarina, Centro de Ciências Agrárias, Departamento de Fitotecnia, Rodovia Admar Gonzaga, 1346, Itacorubi, 88034-001 Florianópolis, SC, Brasil.

5. Autor para correspondência: julianamarcia@yahoo.com.br

\section{Introdução}

A família Bromeliaceae Juss. é composta por 2.885 espécies e 56 gêneros (Luther 2000). Aproximadamente $40 \%$ destas espécies e $73 \%$ dos gêneros podem ser encontrados no Brasil (Leme \& Marigo 1993).

A maioria das espécies pertencentes à família Bromeliaceae é autocompatível (McWilliams 1974, Martinelli 1994). A ornitofilia é encontrada na maioria das espécies (Sazima et al. 1989), mas a melitofilia (Siqueira-Filho 1998, Wendt et al. 2001, 2002, Araújo et al. 2004), a psicofilia (Varassin \& Sazima 2000, Lenzi 
et al. 2006) e a quiropterofilia (Sazima et al. 1989, Sazima et al. 1995) também ocorrem.

A subfamília Pitcairnioideae possui 16 gêneros (Forzza 2001) e aproximadamente 678 espécies (Smith \& Downs 1974). O gênero Dyckia pertence à Pitcairnioideae, é restrito ao sudeste da América do Sul, compreende cerca de 130 espécies (Luther 2000), e ocorre em ambientes terrestres ou rupícolas muito áridos (Benzing 1980). Neste gênero, a estrutura reprodutiva e a pigmentação floral sugerem polinização por insetos (Benzing 1980, Varadarajan \& Brown 1988), porém, os poucos estudos realizados com espécies deste gênero indicam espécies de beija-flores como principais polinizadores (Bernardello et al. 1991, Vosgueritchian \& Buzato 2006).

Algumas bromélias do gênero Dyckia ocorrem como reófitas (Klein 1979), entre elas Dyckia brevifolia Baker. O termo reófita designa espécies vegetais confinadas ao leito de rios e de riachos com corredeira, ocorrendo acima do nível da água, mas sendo regularmente atingidas pelas cheias (van Steenis 1981).

Em Santa Catarina, D. brevifolia ocorre nas margens e ilhas rochosas do Rio Itajaí-Açu, formando populações disjuntas num percurso que se estende de Lontras até Blumenau (Rogalski 2007). Diante da ausência de estudos com bromeliáceas nesse ambiente, este estudo objetivou estudar as características florais, o sistema reprodutivo e os visitantes florais de $D$. brevifolia.

\section{Material e métodos}

O estudo foi conduzido às margens do Rio Itajaí-Açu (22J, 0658960N, 7001402E), na localidade de Subida, Município de Apiúna, Santa Catarina. O clima na região, segundo a classificação de Köppen, é do tipo mesotérmico úmido (Cfa), com verões quentes e com distribuição uniforme das chuvas ao longo do ano (Comitê do Itajaí 2005). A umidade relativa do ar fica em torno de $85 \%$. O Município de Apiúna apresenta temperatura média de $19,7^{\circ} \mathrm{C}$, precipitação média anual variando entre 1.300 e $1.500 \mathrm{~mm}$, com chuvas constantes no verão, e altitude de 87 m (CIASC 2009).

A reófita Dyckia brevifolia ocorre em ambiente com condições bem específicas (corredeira, rocha exposta, sem depósito de sedimentos), os quais ficam parcialmente ou totalmente submersos durante as cheias (Rogalski 2007). Conforme esta autora, neste ambiente, os recursos estão distribuídos de forma discreta, restringindo-se as disjunções rochosas (fraturas, falhas e desplacamentos por descompressão), onde ocorre a instalação e desenvolvimento dos indivíduos desta espécie.

A bromélia $D$. brevifolia é policárpica (a mesma roseta pode florescer e frutificar várias vezes) e apresenta propagação vegetativa (clonal), estando a maioria das rosetas disposta em pequenos grupos, os quais são constituídos por clones. Aproximadamente $13 \%$ das rosetas desta espécie apresentaram sinais e/ou emissão de inflorescência, sendo consideradas reprodutivas (Rogalski 2007).

O estudo foi desenvolvido em dois períodos reprodutivos (de outubro de 2005 até fevereiro de 2006, e de outubro de 2006 até fevereiro de 2007). O padrão fenológico dos indivíduos da espécie foi determinado conforme a classificação de Gentry (1974). O horário de antese e a duração floral foram observados a partir de 30 botões florais (10 inflorescências), marcados em pré-antese. A seqüência de abertura das flores na inflorescência e o número de flores abertas por dia em cada inflorescência foram registrados em 50 inflorescências (50 indivíduos). Além disso, foi observada a duração de cada inflorescência.

Para a caracterização morfológica das flores foram medidos, com auxílio de um paquímetro, o comprimento da flor, o comprimento interno do tubo floral, o diâmetro de abertura da corola e a altura do androceu (da base do filete ao ápice da antera) e do gineceu (da base do ovário ao estigma). Características florais (cor e formato da corola) relacionadas à atração de visitantes também foram registradas.

A quantificação dos grãos de pólen e do número de óvulos por flor foi realizada em cinco flores de plantas distintas, conforme Petri et al. (1976). A razão pólen/óvulo foi calculada de acordo com Cruden (1977). A receptividade estigmática foi testada utilizando o método de atividade da catalase, com peróxido de hidrogênio (10V) (Zeisler 1938), em flores recém abertas e flores abertas ( $1^{\circ}$ e $2^{\circ}$ dia), sendo utilizadas, para cada teste, 10 flores de diferentes inflorescências.

Para avaliar o efeito da remoção do néctar foram marcados 30 botões em pré-antese (10 indivíduos), sendo realizadas medições $(6,9,12,15$ e 18 horas) durante o período de abertura da flor. Também foram marcados 30 botões, em pré-antese, como controle, nos quais a remoção do néctar foi feita somente no final de sua duração, pouco antes da senescência. Em todos os casos foram utilizados microcapilares $(5 \mu \mathrm{L})$. Nas mesmas flores e horários dos tratamentos para quantificação de volume foi avaliada a concentração total de açúcares no néctar, com a utilização de um refratômetro portátil, com escalas de zero a 50 graus BRIX.

Os visitantes florais foram observados diretamente ou com auxílio de binóculo no período das 6 h00 às 20h00, totalizando 60 horas de observação. Durante as visitas (coleta de pólen e/ou néctar), foram registrados: período, recurso coletado e comportamento. Os beija-flores foram identificados através de fotografias e os insetos foram coletados e depositados no Laboratório de Entomologia Agrícola (CCA, Universidade Federal de Santa Catarina - UFSC), sendo ambos identificados por especialistas.

Para caracterizar o sistema reprodutivo foram realizados, em 2005 e 2006, cinco tratamentos para verificação de: agamospermia, autopolinização espontânea e manual, polinização cruzada (xenogamia) e polinização livre (controle). Foram marcadas cinco flores em cada 
inflorescência, sendo utilizada uma para cada tratamento ( $n=50$ inflorescências).

Em todos os tratamentos, exceto controle, as flores em pré-antese foram ensacadas. No tratamento agamospermia as flores foram emasculadas, no de autopolinização espontânea as flores não foram manipuladas e no de autopolinização manual o pólen da própria flor foi depositado sobre seu estigma. No tratamento de polinização cruzada, como as rosetas agrupadas num mesmo grupo podem ser clones (propagação clonal) as flores foram emasculadas e foi depositado pólen proveniente de flores de outro grupo de plantas, no mínimo a 10 metros de distância. A avaliação do sucesso reprodutivo foi feita 30 dias após realização dos experimentos, sendo registrado o número de frutos formados. Para verificar se o número de frutos formados nos tratamentos de polinização diferiu do controle foi elaborada uma tabela de contingência e aplicado o teste Qui-quadrado $\left(\chi^{2} ; P<0,05\right)$ (Steel \& Torrie 1980).

A contagem do número de sementes foi efetuada em 10 dos frutos formados em cada tratamento de polinização. Os testes de germinação de sementes oriundas dos tratamentos de polinização foram conduzidos em germinador, com temperatura $\left(25^{\circ} \mathrm{C}\right)$ e fotoperíodo (14 horas de luz) controlados, no Laboratório de Sementes Florestais (Lasef, UFSC). O delineamento experimental utilizado foi o de blocos inteiramente casualizados com quatro repetições, com 100 sementes cada. Sementes com emissão de radícula foram consideradas germinadas. Para verificar possíveis diferenças no número médio de sementes por fruto e no número médio de sementes germinadas em cada tratamento foram aplicados a análise de variância (ANOVA) e o teste Student-NewmanKeuls (SNK) de separação de médias, com $\alpha=0,05$ (Steel \& Torrie 1980).

Em 30 inflorescências ao longo da área de estudo foi realizada contagem do número de flores e posteriormente do número de frutos formados por inflorescência. Em 10 destas inflorescências foram escolhidos, ao acaso, três frutos do ápice, do meio e da base de cada inflorescência. Para verificar possíveis diferenças no número médio de sementes por fruto, em cada posição da inflorescência, foram utilizadas estatísticas descritivas (média e intervalo de confiança, com $\alpha=0,05)$.

\section{Resultados}

Em 2005 o período de floração iniciou-se no mês de novembro estendendo-se até o final de janeiro de 2006. Em 2006 iniciou-se em outubro estendendo-se até janeiro de 2007. As rosetas emitiram lateralmente uma inflorescência racemosa ou muito raramente duas. Em uma mesma inflorescência ocorreu sobreposição das fenofases (botões, flores abertas, frutos). O número de flores por inflorescência variou de 28 a 92, com média de $60,4 \pm 14,5$ flores $(n=30)$. Cada inflorescência apresentou duração de $15 \pm 3$ dias $(n=50)$.
As medidas dos atributos florais de $D$. brevifolia estão apresentadas na tabela 1 . As flores de $D$. brevifolia apresentam formato tubular e são pediceladas. Cada flor é constituída por um perianto, formado por três sépalas amarelas com o ápice esverdeado e por três pétalas amarelas, estas imbricadas formando um tubo funcional; seis estames, sendo os filetes conatos na base formando um tubo filamentar; e um gineceu trilocular, com estigma trífido conduplicado espiral (figura 1). Foi constatada a presença de um nectário extranupcial em cada sépala de D. brevifolia, o qual apresentava secreção em forma de gotícula, porém, nestes nectários, não foram registrados visitantes.

Tabela 1. Atributos florais de Dyckia brevifolia. Rio ItajaíAçu, SC $(n=30)$.

Table 1. Floral features of Dyckia brevifolia. Itajaí-Açu River, SC $(n=30)$.

\begin{tabular}{lrc}
\hline Atributos florais & Média & $\begin{array}{r}\text { Desvio } \\
\text { padrão }\end{array}$ \\
\hline Comprimento da flor (mm) & 14,9 & 0,7 \\
Lobos da corola (mm) & 6,8 & 0,6 \\
Comprimento do tubo floral (mm) & 7,9 & 0,7 \\
Diâmetro de abertura do tubo (mm) & 5,6 & 0,5 \\
Gineceu (mm) & 8,4 & 0,5 \\
Androceu (mm) & 12,4 & 0,7 \\
Sépalas (mm) & 8,9 & 0,5 \\
Bráctea floral (mm) & 9,8 & 0,3 \\
Comprimento da inflorescência com & 58 & 8,7 \\
flores (cm) & & \\
Escapo floral (cm) & 34 & 8,3 \\
\hline
\end{tabular}

A antese das flores ocorreu ao longo do dia, desde o início da manhã (após as 8h00) até às 16h00, e as flores apresentaram duração de cerca de um dia e meio, sem fechamento à noite. A abertura das flores ocorreu no sentido da base para o ápice da inflorescência e o número de flores abertas por inflorescência por dia variou de 3 a 9 , com média de 6,8 $\pm 1,2$ ( $n=50$ inflorescências).

$\mathrm{Na}$ fase de botão as anteras encontravam-se levemente acima do estigma. Juntamente com o início da antese floral ocorreu a deiscência das anteras, em sentido longitudinal e voltada ao estigma. Com a deiscência, as anteras curvaram-se no sentido externo da flor, o que as deixou na mesma altura do estigma. O pólen permaneceu disponível somente no primeiro dia de abertura floral e o estigma encontrava-se receptivo durante todo o período 

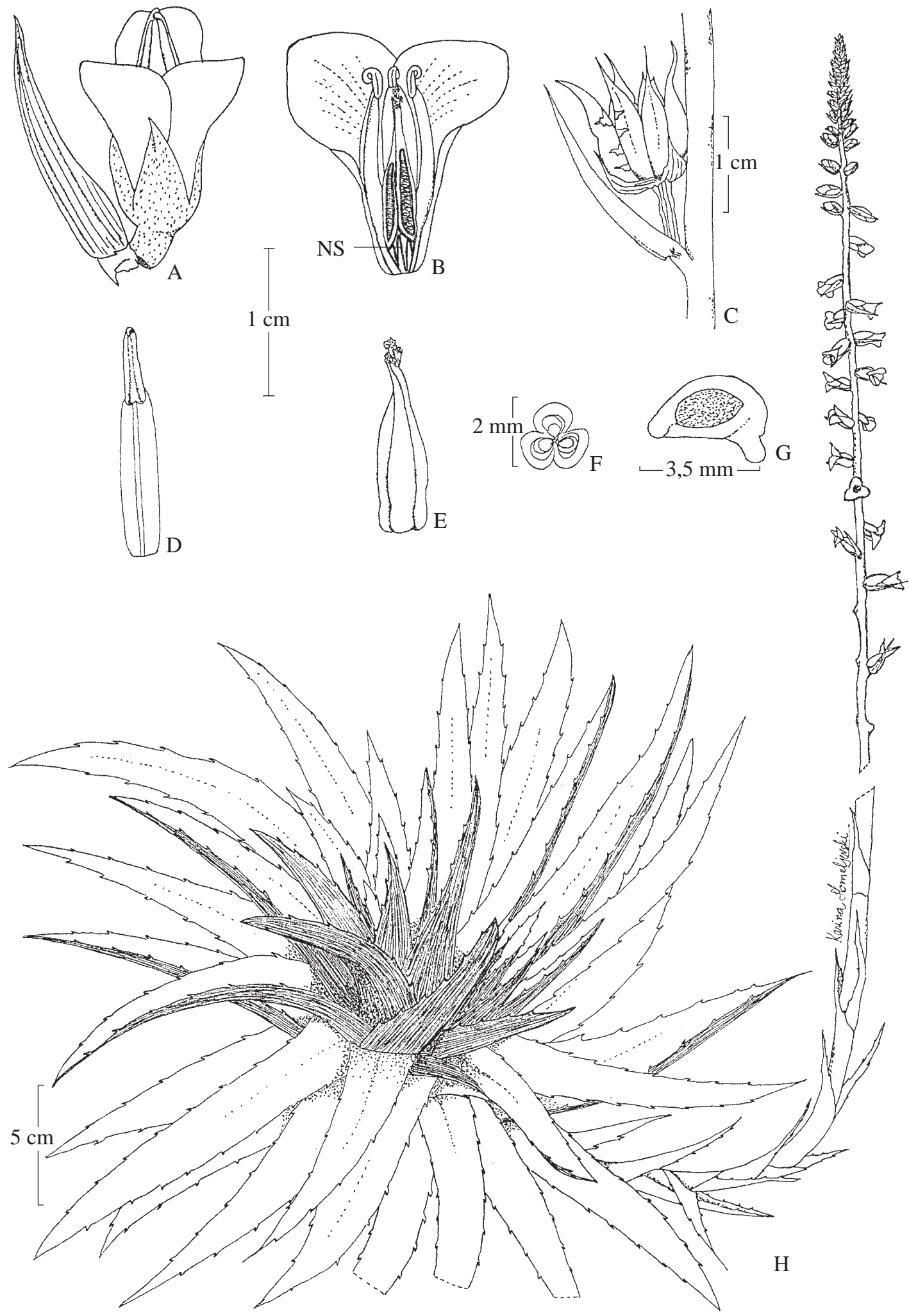

Figura 1. Dyckia brevifolia. A. Flor. B. Flor sem a pétala e estames frontais mostrando o nectário septal (NS). C. Fruto deiscente. D. Estame. E. Gineceu. F. Corte transversal do ovário. G. Semente. H. Hábito. Ilustração K.V. Hmeljevski.

Figure 1. Dyckia brevifolia. A. Flower. B. Flower without frontal petal and stamens showing the septal nectary (NS). C. Dehiscent fruit. D. Stamen. E. Gynoecium. F. Tranversal section of the ovary. G. Seed. H. Habit. Illustration K.V. Hmeljevski. 
de abertura floral. O número médio de grãos de pólen por flor foi de $424.200 \pm 23,5(n=5)$ e o número médio de óvulos por flor foi de 150,4 $\pm 9,2(n=5)$. A razão pólen/óvulo foi de 2.820,5: 1.

O néctar é produzido num nectário septal (figura 1B) e fica acumulado na base da corola, podendo ser acessado através de passagens entre os filamentos dos estames. O volume de néctar não diferiu entre os horários avaliados, exceto às 6 h00 (figura 2A). No segundo dia, às $18 \mathrm{~h} 00$ as flores não produziam mais néctar (figura $2 \mathrm{~A}$ ), sendo que muitas já tinham senescido. $\mathrm{O}$ volume de néctar produzido não diferiu entre flores de primeiro e segundo dia, ocorrendo um maior acúmulo às 6 h00 do segundo dia (figura 2B).

A concentração do néctar foi maior no primeiro dia de abertura floral, exceto no horário das 9h00, em que não diferiu entre flores de primeiro e segundo dia (figura 3). No primeiro dia de abertura da flor a concentração do néctar foi aumentando ao longo do dia, sendo mais elevada às $15 \mathrm{~h} 00$ e às $18 \mathrm{~h} 00$, não diferindo entre si; e no segundo dia a concentração não diferiu entre os horários avaliados (figura 3).

A produção de néctar foi maior com a remoção $(\bar{X}=30,5$; IC $\pm 5,3, \alpha=0,05)$ do que no controle $(\bar{X}=14,2 ;$ IC $\pm 3,3, \alpha=0,05)$. Porém, a concentração do néctar foi maior no controle $(\bar{X}=39,9$; IC $\pm 3,8$, $\alpha=0,05)$ do que com a remoção $(\bar{X}=25,7$; IC $\pm 2,4$, $\alpha=0,05)$.

Na tabela 2 são apresentados os visitantes florais, o recurso coletado, o número e os horários de visitação de cada visitante floral de $D$. brevifolia.



Figura 3. Concentração de açúcar no néctar (\%) durante a abertura floral de Dyckia brevifolia. (Média \pm intervalo de confiança, $\alpha=0,05$; $\square=1$ 음 dia, $\square=2{ }^{\circ}$ dia; $n=30$ ).

Figure 3. Sugar concentration in nectar (\%) per flower throughout the floral aperture at Dyckia brevifolia. (Mean \pm confidence interval, $\alpha=0.05$; $\square=1^{\text {st }}$ day, $\square=2^{\text {nd }}$ day; $n=30$ ).
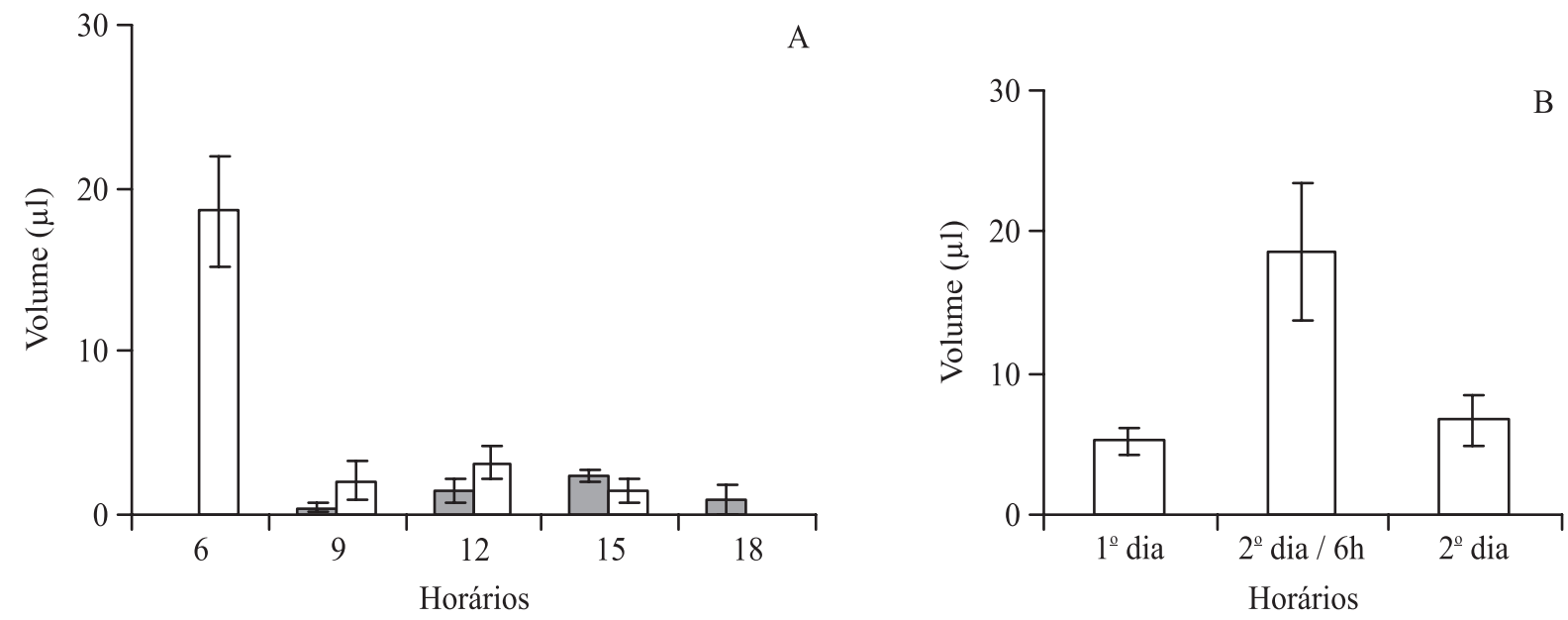

Figura 2. A.Variação no volume de néctar $(\mu \mathrm{L})$ por flor durante a abertura floral de Dyckia brevifolia. B. 1o dia = soma do volume de néctar do $1^{\circ}$ dia $(9 \mathrm{~h} 00,12 \mathrm{~h} 00,15 \mathrm{~h} 00$ e $18 \mathrm{~h} 00) ; 2^{\circ}$ dia/6h = volume de néctar produzido após às $18 \mathrm{~h} 00$ do $1^{\circ}$ dia até às $6 \mathrm{~h} 00$ do $2^{\circ}$ dia; $2^{\circ}$ dia = soma do volume de néctar do 2o dia (9h00 $12 \mathrm{~h} 0015 \mathrm{~h} 00$ e 18h00). (Média \pm intervalo de confiança, $\alpha=0,05 ; \square=1^{\circ}$ dia, $\square=2^{\circ}$ dia; $n=30$ ).

Figure 2. A. Variation in nectar volume $(\mu \mathrm{L})$ per flower throughout the floral aperture of Dyckia brevifolia. B. $1^{\circ}$ dia $=$ sum of the nectar volume of the $1^{\text {st }}$ day $(9 \mathrm{~h} 00,12 \mathrm{~h} 00,15 \mathrm{~h} 00$ and $18 \mathrm{~h} 00) ; 2^{\circ} \mathrm{dia} / 6 \mathrm{~h}=$ nectar volume produced after $18 \mathrm{~h} 00$ of the $1^{\text {st }}$ day to $6 \mathrm{~h} 00$ of the $2^{\text {nd }}$ day; $2^{\circ}$ dia = sum of the nectar volume of the $2^{\text {nd }}$ day $(9 h 00,12 \mathrm{~h} 00,15 \mathrm{~h} 00$ and $18 \mathrm{~h} 00)$. (Mean \pm confidence interval, $\alpha=0.05 ; \square=1^{\text {st }}$ day, $\square=2^{\text {nd }}$ day; $n=30$ ). 
Tabela 2. Número e horário de visitas e recurso floral coletado por visitante floral da reófita Dyckia brevifolia (Bromeliaceae). Rio Itajaí-Açu, SC.

Table 2. Visit number and horary and floral resource collected by floral visitors of the rheophyte Dyckia brevifolia (Bromeliaceae). Itajaí-Açu River, SC.

\begin{tabular}{|c|c|c|c|c|c|}
\hline Ordem & Família & Espécie & $\begin{array}{l}\text { Recurso } \\
\text { coletado }\end{array}$ & $\begin{array}{l}\text { Visitas } \\
\mathrm{n}^{\circ}(\%)\end{array}$ & $\begin{array}{l}\text { Horários de } \\
\text { visitação }\end{array}$ \\
\hline Coleoptera & Chrysomelidae & $\begin{array}{l}\text { Diabrotica speciosa Germar, } 1824 \\
\text { (Galerucinae) }\end{array}$ & pólen & $*$ & $8 \mathrm{~h} 00-18 \mathrm{~h} 00$ \\
\hline Diptera & & Não identificada & néctar & $8 \quad(2,2)$ & $9 h 00-15 h 00$ \\
\hline \multirow[t]{8}{*}{ Hymenoptera } & Apidae & Apis mellifera Linnaeus, 1758 (Apinae) & néctar e pólen & $*$ & 7h00-19h00 \\
\hline & & $\begin{array}{l}\text { Bombus (Fervidobombus) morio } \\
\text { Swederus, } 1787 \text { (Apinae) }\end{array}$ & néctar e pólen & $4(1,1)$ & $9 \mathrm{~h} 00-11 \mathrm{~h} 00$ \\
\hline & & $\begin{array}{l}\text { Bombus (Fervidobombus) pauloensis } \\
\text { Friese, } 1913 \text { (Apinae) }\end{array}$ & néctar e pólen & $10(2,8)$ & 9h00-15h00 \\
\hline & & Centris sp. (Apinae) & pólen & $10(2,8)$ & $9 h 00-17 h 00$ \\
\hline & & $\begin{array}{l}\text { Trigona spinipes Fabricius, } 1793 \\
\text { (Apinae) }\end{array}$ & néctar e pólen & $*$ & 7h00-19h00 \\
\hline & & $\begin{array}{l}\text { Xylocopa (Neoxylocopa) brasilianorum } \\
\text { Linnaeus, } 1767 \text { (Xylocopinae) }\end{array}$ & néctar e pólen & $18(5,0)$ & $10 \mathrm{~h} 00-16 \mathrm{~h} 00$ \\
\hline & Halictidae & Augochloropsis sp. (Halictinae) & pólen & $3(0,8)$ & $15 \mathrm{~h} 00-16 \mathrm{~h} 00$ \\
\hline & & Dialictus sp. (Halictinae) & pólen & $6(1,7)$ & $13 \mathrm{~h} 00-15 \mathrm{~h} 00$ \\
\hline \multirow[t]{6}{*}{ Lepidoptera } & Arctiidae & Espécie não identificada & néctar & $1(0,3)$ & $13 \mathrm{~h} 00-14 \mathrm{~h} 00$ \\
\hline & Hesperiidae & Urbanus sp.1 (Pyrginae) & néctar & $30(8,3)$ & $8 \mathrm{~h} 00-15 \mathrm{~h} 00$ \\
\hline & & Urbanus sp.2 (Pyrginae) & néctar & $6(1,7)$ & $9 \mathrm{~h} 00-11 \mathrm{~h} 00$ \\
\hline & & Espécie não identificada & néctar & $18(5,0)$ & $9 h 00-17 h 00$ \\
\hline & Lycaenidae & $\begin{array}{l}\text { Riodina lycisca Hewitson, } 1853 \\
\text { (Riodininae) }\end{array}$ & néctar & $6(1,7)$ & $13 \mathrm{~h} 00-17 \mathrm{~h} 00$ \\
\hline & Papilionidae & Parides sp. (Papilioninae) & néctar & $2(0,6)$ & 9h00-10h00 \\
\hline \multirow[t]{2}{*}{ Trochiliforme } & Trochilidae & $\begin{array}{l}\text { Amazilia versicolor Vieillot, } 1818 \\
\text { (Trochilinae) }\end{array}$ & néctar & $236(65,4)$ & $6 h 00-19 h 00$ \\
\hline & & $\begin{array}{l}\text { Phaethornis eurynome Lesson, } 1832 \\
\text { (Phaethornithinae) }\end{array}$ & néctar & $1(0,3)$ & $6 h 00-7 h 00$ \\
\hline Passeriformes & Coerebidae & $\begin{array}{l}\text { Coereba flaveola Linnaeus, } 1758 \\
\text { (Coerebinae) }\end{array}$ & néctar & $2(0,6)$ & $6 h 00-7 h 00$ \\
\hline
\end{tabular}

* presente durante todo o horário de visitação. * present through all the visitation period.

Durante a coleta de néctar, as espécies de borboleta (Hesperiidae) não contactaram o estigma. Os demais lepidópteros, o passeriforme Coereba flaveola e o troquilídeo Phaethornis eurynome foram observados num único dia.

O coleóptero Diabrotica speciosa consumia principalmente a corola de $D$. brevifolia e, por vezes, pólen, porém não foi observado contactando o estigma.
A espécie não identificada da Ordem Diptera coletava néctar de várias flores de diferentes inflorescências, mas também não contactava o estigma.

As abelhas Augochloropsis sp., Centris sp. e Dialictus sp. foram observadas coletando pólen, porém sem contactar o estigma. Trigona spinipes foi a visitante mais freqüente e abundante de $D$. brevifolia, podendo ser encontrada em praticamente todas as inflorescências. 
Esta abelha permanecia um longo tempo na mesma flor e inflorescência, raramente se movimentando entre as plantas. Na maior parte do tempo coletava pólen e não tocava o estigma e, por vezes, cortava algumas anteras. Porém, quando coletava néctar depositava pólen na cabeça e tocava o estigma efetuando a polinização. Trigona spinipes apresentou comportamento agressivo, afastando outras espécies de abelhas (Bombus spp. e Xylocopa brasilianorum), assim como as espécies de borboleta, durante as visitas ou mesmo durante o vôo.

Apis mellifera também foi um visitante muito freqüente e abundante. Esta abelha visitava flores da mesma inflorescência e do mesmo grupo de plantas, promovendo polinização. Esta espécie também apresentou comportamento agressivo em relação às outras espécies de abelhas.

As abelhas Xylocopa brasilianorum, Bombus pauloensis e B. morio, apesar de promoverem a polinização, apresentaram baixa freqüência de visitas. Estas espécies introduziam a cabeça e o primeiro par de pernas na corola para coletar néctar e pólen, depositando pólen na cabeça e tocando o estigma. Estas abelhas visitavam vários grupos de rosetas de $D$. brevifolia ao longo da área, principalmente devido ao comportamento agonístico de T. spinipes. Porém, visitavam mais de uma flor em cada inflorescência e mais de uma inflorescência em cada grupo.

O beija-flor Amazilia versicolor apresentou o maior número de visitas (cerca 65\%), com intervalos entre 10 e 30 minutos. Durante as visitas o pólen era depositado no bico deste beija-flor. Em cada visita ao local de estudo, esta espécie visitava praticamente todas as inflorescências de $D$. brevifolia ocorrentes na área, porém visitava mais de uma flor em cada inflorescência e mais de uma inflorescência em cada grupo de rosetas.

Também foi observado que, após as visitas Amazilia versicolor, Bombus spp. e Xylocopa brasilianorum se deslocavam para outras populações da espécie, próximas a área de estudo.

Com relação ao sistema reprodutivo, a porcentagem de frutos formados por tratamento variou de $70 \%$ (agamospermia) a 98\% (controle) (tabela 3). Nos dois anos de avaliação, o tratamento agamospermia apresentou menor formação de frutos que o controle $\left(\chi^{2}=14,58\right.$ em 2005 e $\chi^{2}=13,25$ em 2006; $\left.P<0,05\right)$ e os demais tratamentos não diferiram do controle (tabela 3 ).

O número médio de sementes por fruto e a porcentagem média de sementes germinadas foram menores no tratamento agamospermia e não diferiram entre os demais tratamentos (tabela 3). Além disso, 20\% dos frutos agamospérmicos desenvolveram apenas um ou dois carpelos.

O número de frutos produzidos por inflorescência variou de 28 a 83, com média de 58,3 \pm 13,3, sendo a razão fruto/flor de 0,97 ( $n=30$ inflorescências). Os frutos do ápice apresentaram menor número médio de sementes $(\bar{X}=101,7$; IC $\pm 4,3, \alpha=0,05 ; n=30)$ que os frutos do meio $(\bar{X}=140,9$; IC $\pm 30,4, \alpha=0,05$;

Tabela 3. Porcentagem (\%) de frutos formados, número médio de sementes por fruto e porcentagem (\%) média de sementes germinadas por tratamento de polinização em flores de Dyckia brevifolia, em dois anos de estudo (2005 e 2006), Rio ItajaíAçu, SC.

Table 3. Fruit set (\%), mean number of seeds per fruit, germinated seed (\%) per pollination treatment on flowers of Dyckia brevifolia, on two years of study (2005 and 2006), Itajaí-Açu River, SC.

\begin{tabular}{|c|c|c|c|c|c|c|}
\hline \multirow[t]{2}{*}{ Tratamentos de polinização } & \multicolumn{2}{|c|}{$\begin{array}{l}\% \text { frutos formados } \\
(n=50 / \text { tratamento })\end{array}$} & \multicolumn{2}{|c|}{$\begin{array}{l}\mathrm{n}^{\mathrm{o}} \text { médio de sementes/fruto } \\
\quad(n=10 / \text { tratamento })\end{array}$} & \multicolumn{2}{|c|}{$\begin{array}{c}\% \text { média sementes germinadas } \\
(4 \times 100 / \text { tratamento })\end{array}$} \\
\hline & 2005 & 2006 & 2005 & 2006 & 2005 & 2006 \\
\hline Agamospermia & $70^{*}$ & $72 *$ & $89,5 \mathrm{a}^{* *}$ & 80,3 a & 79,8 a & 75,6 a \\
\hline Autopolinização espontânea & 96 & 92 & $113,4 \mathrm{~b}$ & $112,6 \mathrm{~b}$ & $94,3 \mathrm{~b}$ & $93,6 \mathrm{~b}$ \\
\hline Autopolinização manual & 90 & 92 & $133,6 \mathrm{~b}$ & $135,5 \mathrm{~b}$ & $90,8 \mathrm{~b}$ & $93,1 \mathrm{~b}$ \\
\hline Polinização cruzada & 96 & 92 & $131,3 \mathrm{~b}$ & $133,4 \mathrm{~b}$ & $93,3 \mathrm{~b}$ & $92,8 \mathrm{~b}$ \\
\hline Polinização livre & 98 & 98 & $130,4 \mathrm{~b}$ & $137,6 \mathrm{~b}$ & $96,5 \mathrm{~b}$ & $95,2 \mathrm{~b}$ \\
\hline
\end{tabular}

* Diferiram significativamente do controle pelo teste $\chi^{2}(P<0,05)$; ** mesmas letras indicam diferenças não significativas pelo teste SNK $(\alpha=0,05)$, comparações nas colunas.

* Significatively different from the control according to $\chi^{2}$ test $(P<0.05)$; ** same letters indicate non significant difference according to SNK test $(\alpha=0,05)$, comparisons in the columns. 
$n=30)$ e da base $(\bar{X}=146,3$; IC $\pm 8,7, \alpha=0,05$; $n=30$ ) da inflorescência, os quais não diferiram entre si. O número médio de sementes por fruto foi de $129,6 \pm 24,3(n=90)$. Portanto, estima-se que cada inflorescência produza, em média, 7.555,7 sementes, as quais são aladas e medem cerca de 4 mm (figura 1G).

\section{Discussão}

A estratégia de florescimento individual, caracterizada pelo padrão "steady state” (Gentry 1974), apresentada por $D$. brevifolia, é comum em espécies ornitófilas de Bromeliaceae (Araújo et al. 1994, Sazima et al. 1996, Martinelli 1997, Siqueira-Filho \& Machado 2001, Canela \& Sazima 2003, Lenzi et al. 2006, Machado \& Semir 2006).

As flores de $D$. brevifolia apresentaram antese ao longo do dia e duração de um dia e meio. Esta duração possivelmente está associada à textura carnosa da corola (Siqueira-Filho \& Machado 2006) e poderia aumentar a probabilidade de polinização. A mesma duração foi registrada para Dyckia floribunda Griseb., enquanto $D$. ragonesii Castellanos apresentou duração de três dias, ambas apresentando antese ao longo do dia (Galetto \& Bernardello 1992a). Por outro lado, as flores de $D$. tuberosa (Vell.) Beer apresentaram duração de um dia e antese no início da manhã (Vosgueritchian \& Buzato 2006). Conforme Primack (1985), com certa atividade de polinizadores, a longevidade da flor (duração) determina a probabilidade e o número de vezes que a mesma será visitada.

A presença de nectários extranupciais foi constatada nas sépalas de $D$. brevifolia, porém não foram registrados visitantes. Na mesma região da área de estudo ocorre a reófita $D$. ibiramensis que também apresenta néctarios extranupciais no cálice, os quais são visitados por formigas e outros insetos (obs. pes.). Em outras espécies deste gênero há registro de nectários extranupciais e de interação planta-formiga (Galetto \& Bernardello 1992b, Vesprini et al. 2003, Vosgueritchian \& Buzato 2006). Conforme Benzing (2000), estes nectários ocorrem em pelo menos três gêneros da família Bromeliaceae e ajudam a deter os herbívoros.

A secreção de néctar foi contínua, desde a antese até a senescência da flor, o que também foi observado em outras seis espécies de Pitcairnioideae, das quais duas pertencem ao gênero Dyckia (Galetto \& Bernardello 1992a). Apesar do volume de néctar não diferir entre flores de primeiro e segundo dia, no segundo dia ocorre uma maior disponibilidade de néctar, devido à produção no intervalo entre as $18 \mathrm{~h} 00$ ( $1^{\circ}$ dia) e as $6 \mathrm{~h} 00$ ( $2^{\circ}$ dia). A maior disponibilidade de néctar no último dia de abertura pode ser uma estratégia para garantir sua polinização. O volume de néctar foi maior nas flores em que foi realizada sua remoção do que nas flores do controle, provavelmente em decorrência da evaporação visto que as flores do controle apresentaram maior concentração de açúcares no néctar. Outra causa poderia ser a reabsorção do néctar pelas flores.

A maior duração das flores de $D$. brevifolia, em comparação a outras bromeliáceas (ver Canela \& Sazima 2005), e a produção contínua de néctar poderiam estimular a visitação, aumentando as chances de polinização.

A concentração média de néctar encontrada foi similar a Dyckia floribunda, D. ragonesii (Galetto \& Bernardello 1992a) e D. tuberosa (Vosgueritchian \& Buzato 2006), assim como a de outras espécies de Bromeliaceae polinizadas por beija-flores (Araújo et al. 1994, Martinelli 1994, Machado \& Semir 2006). Além da concentração, a alta produção de néctar e o formato tubular da corola também estariam associados à ornitofilia (Sazima et al. 1996, Buzato et al. 2000).

Por outro lado, a coloração amarela da corola sugere atração para abelhas e o diâmetro de abertura das flores $(5,6 \pm 0,5 \mathrm{~mm})$ permite o acesso, além de beija-flores, de outros visitantes, como insetos (Faegri \& van der Pijl 1980). Desta forma, as características florais de $D$. brevifolia indicam que a espécie poderia atrair beija-flores e insetos, o que foi evidenciado. Visitas de beija-flores e insetos também foram constatadas em outras espécies deste gênero (Bernardello et al. 1991, Vosgueritchian \& Buzato 2006). Segundo Baker (1961), a adaptação a diferentes tipos de polinizadores evoluiria gradualmente e estaria relacionada ao estabelecimento e à maior taxa de sobrevivência das espécies, frente à escassez ou falta dos polinizadores efetivos.

A maioria das rosetas de $D$. brevifolia ocorre em grupos, e possivelmente, devido à propagação clonal, os grupos sejam constituídos principalmente por rametos. Portanto, além da autopolinização (mesma flor), a geitonogamia poderia ocorrer através de cruzamentos entre flores da mesma inflorescência (cada inflorescência oferta, em média, 6,8 flores abertas por dia) e entre inflorescências (clones) dentro de um grupo (mesmo geneto). Assim, a visitação de flores de uma mesma inflorescência ou de diferentes inflorescências de um mesmo grupo de plantas possivelmente promova a geitonogamia.

As borboletas (Hesperiidae) foram consideradas pilhadoras de néctar, pois apresentaram probóscide comprida em relação ao tubo floral de $D$. brevifolia e não tocaram seu estigma. Os Hesperiidae também não 
foram considerados polinizadores de Hohembergia ridleyi (Baker) Mez, por possuirem probóscide muito comprida em relação ao tubo floral (Siqueira-Filho 1998). Em Canistrum aurantiacum E. Morren os lepidópteros foram considerados ineficientes pela baixa freqüência, comportamento e morfologia do corpo (Siqueira-Filho \& Machado 2001). Por outro lado, lepidópteros podem atuar como polinizadores. Duas espécies do gênero Heliconius foram consideradas polinizadores potenciais de Aechmea lindenii (E. Morren) Baker (Lenzi et al. 2006).

Os demais lepidópteros, o troquilídeo Phaethornis eurynome e o passeriforme Coereba flaveola apresentaram visitação em um único dia, sendo considerados visitantes esporádicos. Apesar de não polinizar D. brevifolia, este passeriforme foi considerado co-polinizador de três espécies de bromélias (Sazima \& Sazima 1999).

A abelha Trigona spinipes, quando coletava néctar, contactava o estigma e possivelmente promovia a autopolinização e/ou a geitonogamia, devido a sua permanência por longo período numa mesma flor ou inflorescência. Comportamento similar de T. spinipes também foi evidenciado em espécies de Pitcairnia (Wendt et al. 2001) e em Bromelia antiacantha Bertol. (Canela \& Sazima 2005). Trigona spinipes apresentou comportamento agonístico em relação às abelhas (Xylocopa e Bombus spp.) e às borboletas, o que afetou seus padrões de visitas. Em $B$. antiacantha o comportamento agressivo de $T$. spinipes também afetou o padrão de visitas de Bombus morio e dos beija-flores (Canela \& Sazima 2005).

O coleóptero Diabrotica speciosa, as borboletas (Hesperiidae) e a abelha T. spinipes (quando coletava pólen) apesar de não contatarem o estigma poderiam ocasionar a polinização acidental de $D$. brevifolia, visto que esta bromeliácea possui grande quantidade de pólen e a abertura das anteras é voltada para o estigma.

A abelha Apis mellifera forrageou várias flores da mesma inflorescência ou inflorescências do mesmo grupo de plantas, o que sugere que tenha promovido principalmente autopolinização e geitonogamia. As abelhas A. mellifera e T. spinipes reduzem os recursos florais de $D$. brevifolia, devido ao grande número e freqüência de indivíduos coletando pólen. Apis mellifera também pilhou pólen em $D$. floribunda (Bernardello et al. 1991), o qual seria utilizado por abelhas nativas (Benzing 2000). Conforme Canela \& Sazima (2005), T. spinipes pode reduzir os recursos florais e o efeito sobre a produção de frutos de $B$. antiacantha em condições naturais pode ser negativo, devido à perda de pólen.
A freqüência (10-30 minutos) e o padrão de visitas do beija-flor Amazilia versicolor indicaram esta espécie como principal polinizador de D. brevifolia. Amazilia versicolor comumente visitava inflorescências de praticamente todos os grupos presentes na área, o que promoveria a xenogamia. Porém, visitava mais de uma flor em cada inflorescência e mais de uma inflorescência em cada grupo de plantas, o que promoveria a autofecundação e/ou a geitonogamia. Amazilia versicolor, espécie que ocorre em áreas abertas, foi considerado o principal polinizador de Tillandsia stricta Soland. e T. geminiflora Brongn. (Machado \& Semir 2006), bem como polinizador de Vriesea altodaserrae L.B. Sm. e Wittrockia cyathiformis (Vell.) Leme (Kaehler et al. 2005).

As abelhas Xylocopa brasilianorum e Bombus spp., assim como $A$. versicolor, também visitaram populações próximas às áreas de estudo, indicando que o fluxo gênico via pólen pode ocorrer entre populações.

A razão pólen/óvulo (Cruden 1977), classifica $D$. brevifolia como xenogâmica facultativa, o que corrobora os resultados encontrados quanto ao seu sistema reprodutivo. A espécie $D$. brevifolia é autocompatível, o que também corrobora os resultados encontrados para a maioria das espécies com distribuição restrita (Karron 1987, Hamrick \& Godt 1989, Hamrick et al. 1991, Gitzendanner \& Soltis 2000, Cole 2003). Por outro lado, Dyckia ferox Mez e D. tuberosa são auto-incompatíveis (Bianchi et al. 2000, Vosgueritchian \& Buzato 2006). Contudo, segundo Benzing (1980), a autocompatibilidade e a auto-incompatibilidade coexistem num mesmo gênero. Ainda, na subfamília Pitcairnioideae, Pitcairnia flammea Lindl., P. corcovadensis Wawra e P. albiflos Herb. são autocompatíveis (Wendt et al. 2002).

Além de autocompatível, $D$. brevifolia pode produzir sementes agamospérmicas viáveis. Na subfamília Pitcairnioideae, a agamospermia pode ocorrer em Pitcairnia corcovadensis (32\%) e P. flammea (10,5\%), mas não ocorre em $P$. albiflos (Wendt et al. 2002).

Apesar de $D$. brevifolia apresentar um alto percentual de formação de frutos agamospérmicos e sementes agamospérmicas viáveis, o número, a diversidade e o comportamento dos visitantes florais indicam que a polinização e a fecundação ocorrem na espécie. Além disso, as progênies, avaliadas através de marcadores alozímicos, apresentaram segregação, indicando que são provenientes de fecundação (Rogalski 2007). Portanto, possivelmente a agamospermia se constitua num mecanismo alternativo, caso a polinização não ocorra.

Em $D$. brevifolia, o menor número de sementes encontrado nos frutos do ápice em relação aos frutos do 
meio e da base da inflorescência pode ocorrer devido a um número diferencial de óvulos, pois Vosgueritchian \& Buzato (2006) registraram em D. tuberosa um maior número de óvulos nas flores basais em relação as apicais.

Apesar das sementes de $D$. brevifolia serem aladas, o que sugere dispersão anemocórica, após a deiscência dos frutos as sementes caem e permanecem próximas à planta-mãe (Rogalski 2007). Conforme a autora, em dias de chuva, muito freqüentes no período de reprodução da espécie, as sementes eram carreadas para rio, sendo a hidrocoria sugerida como a principal forma de dispersão das sementes. A hidrocoria (fluxo unidirecional no sentido do rio) desempenha importante papel na estruturação das comunidades vegetais ao longo dos rios (Merritt e Wohl 2002), o que possibilita o estabelecimento de novas populações a longas distâncias da população ancestral, bem como facilita a conexão entre populações separadas espacialmente (Waser et al. 1982, Vogt et al. 2004), como em $D$. brevifolia.

Além da reprodução sexuada e da agamospermia, D. brevifolia também apresenta propagação clonal. A propagação clonal é encontrada na maioria das espécies herbáceas perenes (Richards 1986) e em espécies que ocorrem em locais sujeitos ao alagamento, o que contribui para sua persistência (Menges \& Waller, 1983; Prach \& Pysek, 1994), bem como na maioria dos representantes da família Bromeliaceae (Benzing 2000). Em ambientes que sofrem algum tipo de distúrbio, espécies que se reproduzem assexuadamente têm maior chance de sobreviver (Cook 1983).

A propagação clonal mantém a diversidade genética existente, pois diminui os riscos de mortalidade dos genetos, diluindo o risco entre os rametos, o que pode ajudar a minimizar os efeitos da endogamia (autocompatibilidade) e da deriva genética (populações disjuntas) ao longo das gerações. Além disso, a apomixia, devido ao efeito fundador, pode ser de extrema importância na colonização e no estabelecimento de novas populações (acelerando o crescimento da colônia e aumentando as chances de manutenção dos genetos), diminuindo assim os efeitos da deriva genética. Michaels \& Bazzaz (1989) demonstraram que plantas apomíticas apresentam maior facilidade para colonizar ambientes com distúrbios.

Com relação à reprodução sexuada, as flores de $D$. brevifolia apresentaram tanto características ornitófilas como melitófilas, sendo polinizadas pelos dois agentes. Aparentemente a utilização dos recursos florais por visitantes que não promovem a polinização não influenciou o sucesso reprodutivo da espécie. A autocompatibilidade, apresentada por D. brevifolia, aliada ao comportamento dos polinizadores indicam que as principais formas de polinização promovidas são a autopolinização e a geitonogamia, sendo que ambas produzem endogamia. A possibilidade de ocorrência da xenogamia é muito importante, pois pode minimizar os efeitos da endogamia, assim como gerar diversidade genética. Espécies autógamas geralmente apresentam maior sucesso reprodutivo que alógamas, assim como a autogamia tem sido considerada vantajosa em hábitats marginais ou com distúrbios (Richards 1986), que é o caso do ambiente ocupado por $D$. brevifolia.

O predomínio da autopolinização e da geitonogamia, sugerem que o fluxo gênico via pólen prevalece dentro das populações. Conforme Rogalski (2007) a espécie apresentou alta divergência genética entre populações $\left(\hat{F}_{S T}=0,376\right)$. Por outro lado, a hidrocoria pode indicar que a dispersão de sementes prevaleça entre populações. Estudos neste sentido poderão ajudar a entender melhor os mecanismos de dispersão de $D$. brevifolia.

Os representantes da família Bromeliaceae são conhecidos pela ocupação de ambientes com fatores limitantes (luz, água, nutrientes), bem como a maioria das espécies apresenta reprodução sexuada e propagação clonal (Benzing 2000). A reófita D. brevifolia também ocupa ambiente com fatores adversos (escassez de água e de nutrientes, rocha exposta, temperaturas elevadas, alagamento e correnteza). Desta forma, as várias estratégias apresentadas por $D$. brevifolia podem ser vantajosas para sua manutenção nesse ambiente.

Agradecimentos - Agradecemos ao Dr. Afonso Inácio Orth (UFSC) pela identificação das espécies de abelha, ao Dr. André Victor Lucci Freitas (Unicamp) pela identificação das espécies de borboleta e ao Msc. Vitor de Queiroz Piacentini pela identificação das espécies de beija-flor. Agradecemos também a Capes pela concessão de bolsa a primeira autora deste manuscrito.

\section{Referências bibliográficas}

ARAÚJO, A.C., FISCHER, E.A. \& SAZIMA, M. 1994. Floração seqüencial e polinização de três espécies de Vriesea (Bromeliaceae) na região da Juréia, sudeste do Brasil. Revista Brasileira de Botânica 17:113-118.

ARAÚJO, A.C., FISCHER, E.A. \& SAZIMA, M. 2004. As bromélias na região do Rio Verde. In Estação da JuréiaItatins. Ambiente físico, flora e fauna (O.A.V. Marques \& W. Duleba, eds.). Holos, São Paulo, p.162-171.

BAKER, H.G. 1961. The adaptation of flowering plants to nocturnal and crepuscular pollinators. The Quarterly Revue of Biology 36:64-73. 
BENZING, D.H. 1980. The biology of the bromeliads. Mad River Press, California.

BENZING, D.H. 2000. Bromeliaceae: profile of an adaptive radiation. Cambridge University Press, Cambridge.

BERNARDELLO, G., GALETTO, L. \& JULIANI, H.R. 1991. Nectar and nectary structure in some Argentinean Bromeliaceae. Annals of Botany 67: 401-411.

BIANCHI, M.B., GIBBS, P.E., PRADO, D.E. \& VESPRINI, J.L. 2000. Studies on the breeding systems of understory species of a Chaco woodland in NE Argentina. Flora 195:339-348.

BUZATO, S., SAZIMA, M. \& SAZIMA I. 2000. Hummingbird-pollinated floras at three Atlantic Forest sites. Biotropica 32:824-841.

CANELA, M.B.F. \& SAZIMA, M. 2003. Aechmea pectinata: a hummingbird-dependent bromeliad with inconspicuous flowers from the rainforest in South-eastern Brazil. Annals of Botany 92:731-737.

CANELA, M.B.F. \& SAZIMA, M. 2005. The pollination of Bromelia antiacantha (Bromeliaceae) in the southeastern Brazil: ornithophilous versus melittophilous features. Plant Biology 7:411-416.

CIASC - Centro de Informática e Automação de Santa Catarina. 2009. Apiúna. http://www.sc.gov.br/ portalturismo/Default.asp?CodMunicipio=232\&Pag=1 (Acesso em 23/05/2009).

COLE, C.T. 2003. Genetic variation in rare and common plants. Annual Reviews Ecology, Evolution and Systematics 34:213-237.

COMITÊ DO ITAJAÍ. 2005. A Bacia hidrográfica do Rio Itajaí-Açu. http://www.comiteitajai.org.br/hp.pdf (Acesso em 28/10/2005).

COOK, R.E. 1983. Clonal plant populations. American Scientist 71:244-253.

CRUDEN, R.W. 1977. Pollen-ovule ratios: a conservative indicator of breeding systems in flowering plants. Evolution 31:32-46.

FAEGRI, K. \& VAN DER PIJL, L. 1980. The principles of pollination ecology. Pergamon Press, New York.

FORZZA, R.C. 2001. Filogenia da tribo Puyeae Wittm. e revisão taxonômica do gênero Encholirium Mart. ex Schult. \& Schult. F. (Pitcairnioideae-Bromeliaceae). Tese de doutorado, Universidade de São Paulo, São Paulo.

GALETTO, L. \& BERNARDELLO, L. 1992a. Nectar secretion pattern and removal effects in six argentinean Pitcairnioideae (Bromeliaceae). Botanica Acta 105: 292-299.

GALETTO, L. \& BERNARDELLO, L. 1992b. Extrafloral nectaries that attracted ants in Bromeliaceae: structure and nectar composition. Canadian Journal of Botany 70:1101-1106.

GENTRY, A.H. 1974. Flowering phenology and diversity in tropical Bignoniaceae. Biotropica 6:64-68.
GITZENDANNER, M.A. \& SOLTIS, P.S. 2000. Patterns of genetic variation in rare and widespread plant congeners. American Journal of Botany 87:783-792.

HAMRICK, J.L. \& GODT, M.J.W. 1989. Allozyme diversity in plant species. In Plant population genetics, breeding and genetic resources (A.D.H. Brown, M.T. Cleg, A.L. Kahler \& B.S. Weir, eds.). Sinauer, Suderland, p.43-63.

HAMRICK, J.L., GODT, M.J.W., MURAWSKI, D.A. \& LOVELESS, M.D. 1991. Correlations between species traits and allozyme diversity: implications for conservation biology. In Genetics and conservation of rare plants (D.A.S Falk \& K.E Holsinger, eds.). Oxford University Press, Oxford, p.75-86.

KAEHLER, M., VARISSIN, G. \& GOLDENBERG, R. 2005. Polinização em uma comunidade de bromélias em floresta atlântica alto-montana no estado do Paraná, Brasil. Revista Brasileira de Botânica 28:219-228.

KARRON, J.D. 1987. A comparison of levels of genetic polymorphism and self-compatibility in geographically restricted and widespread plant congeners. Evolutionary Ecology 1:47-58.

KLEIN, R.M. 1979. Reófitas no Estado de Santa Catarina, Brasil. Anais do $30^{\circ}$ Congresso da Sociedade Botânica do Brasil. Campo Grande, Sociedade Botânica do Brasil, São Paulo, p.159-169.

LEME, E.M.C. \& MARIGO, L.C. 1993. Bromélias na natureza. Marigo Comunicação Visual, Rio de Janeiro.

LENZI, M., MATOS, J.Z. \& ORTH, A.I. 2006. Variação morfológica e reprodutiva de Aechmea lindenii (E. Morren) Baker var. lindenii (Bromeliaceae). Acta Botanica Brasilica 20:487-500.

LUTHER, H.E. 2000. An alphabetical list of bromeliad binomials. http://www.selby.org/research/bic/Binom_ 2000_Alpha.pdf (Acesso em 06/01/2003).

MACHADO, C.G. \& SEMIR, J. 2006. Fenologia da floração e biologia floral de bromeliáceas ornitófilas de uma área da Mata Atlântica do Sudeste brasileiro. Revista Brasileira de Botânica 29:163-174.

MARTINELLI, G. 1994. Reproductive biology of Bromeliaceae in the Atlantic rainforest of Southeastern Brazil. PhD thesis. School of Biological and Medical Sciences, University of St. Andrews, Scotland.

MARTINELLI, G. 1997. Biologia reprodutiva de Bromeliaceae na Reserva Ecológica de Macaé de Cima. In Serra de Macaé de Cima: Diversidade florística e conservação em Mata Atlântica (H.C. Lima, R.R. \& Guedes-Bruni, eds.). IP/JBRJ, Rio de Janeiro, p.213-250.

MCWILLIAMS, E.L. 1974. Evolucionary ecology. In Bromeliaceae (Pitcairnioideae). Flora Neotropica Monograph (L.B. Smith \& R.J. Downs, eds.) Hafner Press, New York, p.40-45.

MENGES, E.S. \& WALLER, D.M. 1983. Plant strategies in relation to elevation and light in floodplain herbs. American Naturalist 122:454-473. 
MERRITT, D.M. \& WOHL, E.E. 2002. Processes governing hydrochory along rivers: hydraulics, hydrology, and dispersal phenology. Ecological Application 12:10711087.

MICHAELS, H.J. \& BAZZAZ, F.A. 1989. Individual and population responses of sexual and apomictic plants to environmental gradients. The American Naturalist 134:190-207.

PETRI, J.L., PASQUAL, M. \& PELLEGRIN, M. 1976. Estudo da quantidade de pólen em diversas cultivares de macieira (Malus sp.). Anais do III Congresso Brasileiro de Fruticultura, Rio de Janeiro, Sociedade Brasileira de Fruticultura, Campinas, p.467-471.

PRACH, K. \& PYSEK, P. 1994. Clonal plants - what is their role in succession? Folia Geobotanica \& Phytotaxonomica 29:307-320.

PRIMACK, R.B. 1985. Longevity of individual flowers. Annual Review of Ecology and Systematics 16: 15-37.

REITZ, R. 1983. Bromeliáceas e a malária-bromélia endêmica. In Flora ilustrada catarinense (R. Reitz, ed.). Herbário Barbosa Rodrigues, Itajaí, p.1-808.

RICHARDS, A.J. 1986. Plant breeding systems. Allen \& Unwin, London.

ROGALSKI, J.M. 2007. Biologia da conservação da reófita Dyckia brevifolia Baker (Bromeliaceae) no Rio ItajaíAçu, SC. Tese de doutorado, Universidade Federal de Santa Catarina, Florianópolis.

SAZIMA, I., VOGEL, S. \& SAZIMA, M. 1989. Bat pollination of Encholirium glaziovii, a terrestrial bromeliad. Plants Systematics and Evolution 168:167179.

SAZIMA, M., BUZATO, S. \& SAZIMA, I. 1995. Bat pollination of Vriesea in Southeastern Brazil. Bromelia 2:29-37.

SAZIMA, I., BUZATO, S. \& SAZIMA, M. 1996. An assemblage of hummingbird-pollined flowers in a montane forest in southeastern Brazil. Botanica Acta 109:149-160.

SAZIMA, M. \& SAZIMA, I. 1999. The perching bird Coereba flaveola as a co-pollinator of bromeliad flowers in southeastern Brazil. Canadian Journal of Zoology $77: 47-51$.

SIQUEIRA-FILHO, J.A. 1998. Biologia floral of Hohenbergia ridleyi (Baker) Mez. Bromélia 5:3-13.

SIQUEIRA-FILHO, J.A. \& MACHADO, I.C.S. 2001. Biologia reprodutiva de Canistrum aurantiacum E. Morren (Bromeliaceae) em remanescente da Floresta Atlântica, Nordeste do Brasil. Acta Botanica Brasilica 15:427-444.
SIQUEIRA-FILHO, J.A. \& MACHADO, I.C.S. 2006. Floração e polinização das bromélias da Mata Atlântica nordestina. In Fragmentos de Mata Atlântica do Nordeste; biodiversidade, conservação e suas bromélias (J.A. Siqueira-Filho \& E.M.C. Leme, eds.). Andrea Jakobsson Estúdio, Rio de Janeiro, p.159-189.

SMITH, L.B. \& DOWNS, R.J. 1974. Bromeliaceae (Pitcairnioideae). Flora Neotropica Monograph 14: 1-662.

STEEL, R.G.D. \& TORRIE, J.H. 1980. Principles and procedures of statistics: a biometrical approach. McGraw-Hill Book Company, New York.

VAN STEENIS, C.G.C.J. 1981. Rheophytes of the world. Sijthoff \& Noordhoff, Maryland.

VARADARAJAN, G.S. \& BROWN, G.K. 1988. Morphological variation of some features of subfamily Pticarnioideae (Bromeliaceae) and their significance in pollination biology. Botanical Gazette 149:82-91.

VARASSIN, I.G. \& SAZIMA, M. 2000. Recursos de Bromeliaceae utilizados por beija-flores e borboletas em Mata Atlântica no Sudeste do Brasil. Boletim do Museu de Biologia Mello Leitão, nova série 11/12:57-70.

VESPRINI, J.L., GALETTO, L. \& BERNARDELLO, G. 2003. The beneficial effect of ants on the reproductive success of Dyckia floribunda (Bromeliaceae), an extrafloral nectary plant. Canadian Journal of Botany 81:24-27.

VOGT, K., RASRAN, L. \& JENSEN, K. 2004. Water-borne seed transport and seed deposition during flooding in a small river-valley in Northern Germany. Flora 199: 377-388.

VOSGUERITCHIAN, S.B. \& BUZATO, S. 2006. Reprodução sexuada de Dyckia tuberosa (Vell.) Beer (Bromeliaceae, Pitcairnioideae) e interação planta-animal. Revista Brasileira de Botânica 29:433-442.

WASER, N.M., VICKERY, R.K. \& PRICE, M.V. 1982. Patterns of seed dispersal and population differentiation in Mimulus guttatus. Evolution 36:753-761.

WENDT, T., CANELA, M.B.F., FARIA, A.P.G. \& RIOS, R.I. 2001. Reproductive biology and natural hybridization between two endemic species of Pitcairnia (Bromeliaceae). American Journal of Botany 88:17601767.

WENDT, T., CANELA, M.B.F., KLEIN, D.E. \& RIOS, R.I. 2002. Selfing facilitates reproductive isolation among three sympatric species of Pitcairnia (Bromeliaceae). Plant Systematics and Evolution 232:201-212.

ZEISLER, M. 1938. Über die Abgrenzung der eigentlichen Naberfläche mit Hilfe von reaktionen. Beihefte zum Botanischen Zentrablatt 58:308-318. 